\title{
Correlation of Thrombectomy Maneuver Count with Recanalization Success and Clinical Outcome in Patients with Ischemic Stroke
}

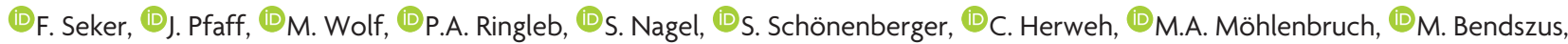 \\ and ${ }^{1}$ M. Pham
}

\begin{abstract}
BACKGROUND AND PURPOSE: In the treatment of acute thromboembolic stroke, the effectiveness and success of thrombus removal when using stent retrievers is variable. In this study, we analyzed the correlation of thrombectomy maneuver count with a good clinical outcome and recanalization success.
\end{abstract}

MATERIALS AND METHODS: One hundred and four patients with acute occlusion of the middle cerebral artery or the terminal internal carotid artery who were treated with thrombectomy were included in this retrospective study. A good clinical outcome was defined as a 90-day mRS of $\leq 2$, and successful recanalization was defined as TICI $2 b-3$.

RESULTS: The maneuver count ranged between 1-10, with a median of 2. Multivariate logistic regression analyses identified an increasing number of thrombectomy maneuvers as an independent predictor of poor outcome (adjusted OR, $0.59 ; 95 \% \mathrm{Cl}, 0.38-0.87 ; P=.011$ ) and unsuccessful recanalization (adjusted $\mathrm{OR}, 0.48 ; 95 \% \mathrm{Cl}, 0.32-0.66 ; P<.001$ ). A good outcome was significantly more likely if finished within 2 maneuvers compared with 3 or 4 maneuvers, or even more than 4 maneuvers $(P<.001)$.

CONCLUSIONS: An increasing maneuver count correlates strongly with a decreasing probability of both good outcome and recanalization. The probability of successful recanalization decreases below $50 \%$ if not achieved within 5 thrombectomy maneuvers. Patients who are recanalized within 2 maneuvers have the best chance of achieving a good clinical outcome.

$\mathbf{R}$ ecent trials showed that mechanical thrombectomy is effective in acute ischemic stroke caused by large vessel occlusion. ${ }^{1-7}$ The speed and success of thrombus removal is variable. ${ }^{8-12}$ Often, several thrombectomy maneuvers are necessary to restore antegrade flow and cerebral perfusion. However, it is uncertain whether flow restoration after multiple thrombectomy maneuvers is still followed by a good clinical outcome. Currently, there is no consensus on a maximum number of maneuver attempts in cases where the thrombus cannot be removed promptly. Hence, the decision to abort the procedure for technical futility is mostly at the discretion of the individual operator. To address this question, we retrospectively analyzed the impact of thrombectomy maneuver count on recanalization and clinical outcome.

\footnotetext{
Received November 7, 2016; accepted after revision March 3, 2017.

From the Departments of Neuroradiology (F.S., J.P., M.W., C.H., M.A.M., M.B., M.P.) and Neurology (P.A.R., S.N., S.S.), Heidelberg University Hospital, Heidelberg, Germany; and Department of Neuroradiology (M.P.), Würzburg University Hospital, Würzburg, Germany.

Please address correspondence to Dr. Fatih Seker, Im Neuenheimer Feld 400, 69120 Heidelberg, Germany; e-mail: fatih.seker@med.uni-heidelberg.de

http://dx.doi.org/10.3174/ajnr.A5212
}

\section{MATERIALS AND METHODS}

\section{Patient Selection}

Between January 2012 and November 2014, all consecutive patients undergoing thrombectomy for the treatment of acute ischemic stroke were collected in a prospective data base and analyzed retrospectively. Inclusion criteria for this study were acute occlusion of the M1 segment of the middle cerebral artery or terminal internal carotid artery, premorbid mRS score of $\leq 2$, and the primary usage of Solitaire FR (Covidien, Irvine, California) or Trevo (Stryker, Kalamazoo, Michigan) stent retrievers. Patients who underwent concomitant stent placement of intracranial arteries during the procedure were excluded. The study was approved by our local ethics committee.

\section{Data Acquisition}

Baseline demographic data, initial NIHSS score, prestroke mRS, and mRS score at 90 days after stroke onset were regularly documented by neurologists. A good clinical outcome was defined as a 90 -day $m R S$ score of $\leq 2$. An unfavorable outcome was defined as a 90 -day mRS score of $>2$.

\section{Image Analysis}

The reader was blinded to clinical data. Baseline ASPECTS was determined on pre-interventional diffusion-weighted sequences 
Table 1: Univariate analysis of data according to recanalization success

\begin{tabular}{lccc}
\hline \multicolumn{1}{c}{ Characteristics } & $\begin{array}{c}\text { Successful } \\
\text { Recanalization }(\boldsymbol{n}=83)\end{array}$ & $\begin{array}{c}\text { Unsuccessful } \\
\text { Recanalization }(\boldsymbol{n}=21)\end{array}$ & $\boldsymbol{P}$ Value \\
\hline Age, yr (mean, SD) & $68.8(15.6)$ & $69.7(14.3)$ & .005 \\
Female, no. (\%) & $52(62.7)$ & $8(38.1)$ & .051 \\
Hypertension, no. (\%) & $64(77.1)$ & $10(47.6)$ & .045 \\
Diabetes mellitus, no. (\%) & $15(18.1)$ & $2(9.5)$ & .733 \\
Prestroke mRS, median (IQR) & $0(0-1)$ & $0(0-1)$ & .910 \\
Initial NIHSS score, median (IQR) & $17(14-21.75)$ & $18(14.75-23.25)$ & .420 \\
Initial ASPECTS, median (IQR) & $8(7-9)$ & $8(7-9)$ & .673 \\
Initial occlusion site, no. (\%) & & & .311 \\
$\quad$ Carotid T & $28(33.7 \%)$ & $10(47.6 \%)$ & \\
Ml & $55(66.3 \%)$ & $11(52.4 \%)$ & .598 \\
Intravenous tPA, no. (\%) & $56(67.5 \%)$ & $16(76.2 \%)$ & $<.001$ \\
Maneuver count, median (IQR) & $2(1-3)$ & $5(3-7)$ & .295 \\
Onset to TICI, min (median, IQR) & $310(224-401)$ & $281(219-324)$ & \\
\hline
\end{tabular}

Note:-Carotid T indicates terminal internal carotid artery; IQR, interquantile range; $\mathrm{Ml}, \mathrm{Ml}$ segment of the middle cerebral artery.

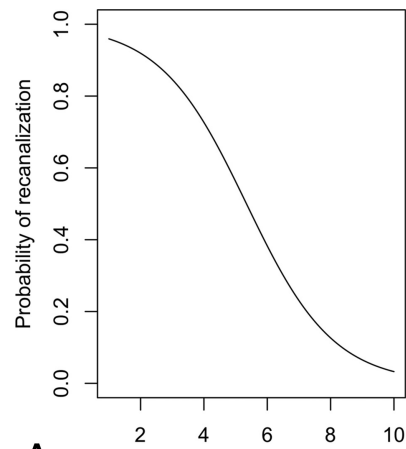

A Thrombectomy maneuvers count

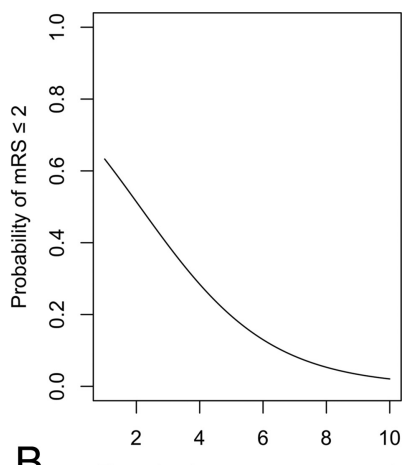

Thrombectomy maneuvers count
FIGURE. A, Logistic regression curve representing an estimate of the probability of successful recanalization (TICI score of $2 b$ or 3 ), depending on the thrombectomy maneuver count $(P<.001)$. B, Logistic regression curve representing an estimate of the probability of a good clinical outcome (90-day mRS score of $\leq 2)$, depending on the thrombectomy maneuver count $(P<.001)$.

in MR imaging or nonenhanced CT scans. TICI scores were assessed on the final angiographic series. A TICI score of $2 \mathrm{~b}$ or 3 (subtotal or complete perfusion) was regarded as successful recanalization. The thrombectomy maneuver count was regularly reported by the performing neurointerventionalist. The reported maneuver count included the use of any additional stent retriever during thrombectomy and was not limited to Solitaire FR or Trevo. Sole thrombus aspiration attempts were not evaluated as a thrombectomy maneuver.

\section{Statistical Methods}

Statistical analyses were performed with R version 3.2.2 (http:// www.r-project.org/) and RStudio version 0.99 (http://rstudio. org/download/desktop). Ninety-day mRS scores are presented as median and interquantile range. Univariate analyses comparing demographic variables that were potentially relevant for predicting the clinical outcome and recanalization were performed by using a Mann-Whitney $U$ test for continuous data and Fisher exact test for categoric variables. A multivariate model was applied to assess the association of the maneuver count with the TICI score and 90-day mRS score, adjusting for those variables that showed univariate association $(P<.05)$. Odds ratios and $95 \%$ confidence intervals were estimated. Differences in the 90 -day mRS score between various groups were analyzed by using a KruskalWallis rank sum test. Statistical significance was set at $P<.05$.

\section{RESULTS}

Of the 250 reviewed records of stroke patients with any intracranial occlusion undergoing thrombectomy at our institution, 104 patients met the inclusion criteria for this retrospective study. Among these patients, $57.7 \%$ were women, and the mean age was $69.0( \pm 14.3)$ years.

Eighty-eight patients $(84.6 \%)$ were treated under general anesthesia, and 16 patients $(15.4 \%)$ were treated under conscious sedation.

The following stent retrievers were used primarily: Solitaire in all cases and Trevo in 7 cases $(6.7 \%)$. If recanalization could not be achieved by using Solitaire or Trevo, the following devices were used: Catch Mini (Balt, Montmorency, France) in 3 cases (2.9\%), ERIC (MicroVention, Tustin, California) in 1 case $(0.9 \%)$, Capture LP (MindFrame, Irvine, California) in 1 case $(0.9 \%)$, and Aperio (Acandis, Pforzheim, Germany) in 1 case $(0.9 \%)$.

The median number of thrombectomy maneuvers was 2 (range, 1-10). Eleven patients (10.6\%) underwent concomitant stent placement of the proximal internal carotid artery. A total of $79.8 \%$ of the patients were successfully recanalized (TICI score of $2 \mathrm{~b}$ or 3 ). A TICI score of $2 \mathrm{a}$ was achieved in $14.4 \%$. In $3.8 \%$ of the patients, no sufficient recanalization was achieved (TICI score of 0 or 1). A good clinical outcome was recorded in $41.3 \%$ of the patients (90-day mRS score of $\leq 2$ ).

In univariate analysis (Table 1 ), successful recanalization was associated with lower age $(P=.005)$, hypertension $(P=.045)$, and lower maneuver count $(P<.001)$. The univariate analysis also revealed that the chance of successful recanalization decreased below $50 \%$ after 5 thrombectomy maneuvers (Fig $1 A$ ). In adjusted multivariate logistic regression, the maneuver count was an independent predictor of successful recanalization (adjusted OR, 0.48; 95\% CI, 0.32-0.66; $P<.001)$.

In another univariate analysis (Table 2$)$, good clinical outcome was significantly associated with lower age $(P<.001)$, lower prestroke mRS $(P=.020)$, lower initial NIHSS score $(P=.025)$, lower maneuver count $(P<.001)$, successful recanalization $(P=$ $.042)$, and short onset-to-recanalization time $(P=.016)$. In a multivariate logistic regression analysis adjusting for these variables, the maneuver count appeared to be an independent predictor of good clinical outcome (adjusted OR, 0.59; 95\% CI, $0.38-$ $0.87 ; P=.011)$. As shown in Fig $1 B$, patients who were recanalized within 2 thrombectomy maneuvers had a $50 \%-60 \%$ chance of a good outcome ( $n=51$; median 90-day mRS score of 2 ; interquantile range, 1-4). Chances of a good outcome were significantly lower when 3 or 4 maneuvers ( $n=34$; median 90-day mRS score of 3 ; interquantile range, 2-4), or even more than 4 maneuvers ( $n=16$; median 90-day mRS score of 4 ; interquantile range, $3.5-6)$ were required for recanalization $(P<.001)$. Only 1 of 16 patients with more than 4 thrombectomy maneuvers had a good neurologic outcome. 
Table 2: Univariate analysis of data according to clinical outcome ${ }^{a}$

\begin{tabular}{|c|c|c|c|}
\hline Characteristics & $\begin{array}{l}\text { Good Outcome } \\
\qquad(n=43)\end{array}$ & $\begin{array}{l}\text { Poor Outcome } \\
\qquad(n=59)\end{array}$ & $P$ Value \\
\hline Age, yr (mean, SD) & $61.4(17.3)$ & $74.6(10.8)$ & $<.001$ \\
\hline Female, no. (\%) & $27(62.8)$ & $32(54.2)$ & .423 \\
\hline Hypertension, no. (\%) & $27(62.8 \%)$ & $46(78.0 \%)$ & .068 \\
\hline Diabetes mellitus, no. (\%) & $5(11.6 \%)$ & $12(20.3 \%)$ & .285 \\
\hline Prestroke mRS, median (IQR) & $0(0-0)$ & $1(0-1)$ & .020 \\
\hline Initial NIHSS score, median (IQR) & $15(12-20)$ & $19(16-22)$ & .025 \\
\hline Initial ASPECTS, median (IQR) & $8(7-9)$ & $8(7-8)$ & .155 \\
\hline Initial occlusion site, no. (\%) & & & .838 \\
\hline Carotid T & $14(38 \%)$ & $22(37 \%)$ & \\
\hline $\mathrm{M} 1$ & $23(62 \%)$ & $38(63 \%)$ & \\
\hline Intravenous tPA, no. (\%) & $33(76.7 \%)$ & $37(62.7 \%)$ & .194 \\
\hline Maneuver count, median (IQR) & $2(1-3)$ & $3(2-4.25)$ & $<.001$ \\
\hline Onset to $\mathrm{TICl}$, min (median, IQR) & $254(193.25-357)$ & $324(273.5-429)$ & .016 \\
\hline Recanalization, no. (\%) & & & .042 \\
\hline $\mathrm{TICl}$ score $0-2 \mathrm{a}$ & $4(9.3 \%)$ & $16(27.1 \%)$ & \\
\hline $\mathrm{TICl}$ score $2 \mathrm{~b}$ or 3 & $39(90.7 \%)$ & $43(72.9 \%)$ & \\
\hline
\end{tabular}

Note:-Carotid T indicates terminal internal carotid artery; IQR, interquantile range; Ml, Ml segment of the middle cerebral artery.

${ }^{a}$ Two patients were lost to follow-up.

\section{DISCUSSION}

In mechanical thrombectomy, it is still unclear how many maneuvers should be attempted in cases where the occluding thrombus cannot be removed easily (ie, where sufficient recanalization according to TICI $2 \mathrm{~b} / 3$ cannot be achieved with a single or few maneuvers). The decision of when to abort the thrombectomy procedure after encountering technical difficulties in retrieving the thrombus is made mainly at the discretion of the operator and not based on empirical evidence. Therefore, we retrospectively studied the impact of the thrombectomy maneuver count on recanalization and clinical outcome in patients with acute ischemic stroke caused by occlusion of the terminal internal carotid artery or M1 segment.

This study confirms that achieving flow restoration within a few thrombectomy maneuvers is important. With every thrombectomy maneuver, we found that the probability of a favorable outcome, defined as mRS score $\leq 2$, decreases significantly. In addition, our results demonstrate that the number of thrombectomy maneuvers is strongly correlated with the probability of successful recanalization itself (TICI score of $2 b$ or 3 ). Patients who were recanalized within 2 maneuvers had the best chance of achieving a good outcome.

The fundamental question is whether the thrombectomy procedure should be aborted if recanalization cannot be achieved within a few maneuvers. In our cohort, sufficient flow restoration was highly unlikely if more than 5 thrombectomy maneuvers were necessary. After 4 thrombectomy maneuvers, there is almost no chance of a good clinical outcome. However, we refrain from suggesting a clear cutoff as a recommendation of how many thrombectomy attempts should be undertaken because, obviously, any such value would be arbitrary. Nonetheless, we provide the first analysis of the association between maneuver count and technical as well as clinical success. These results may help to empirically inform individual decisions for when to abort a procedure and, thus, define it as technically futile.

It is not clear why the thrombectomy maneuver count needed for recanalization varies and why, based on our results, it is closely associated with clinical outcome and with the efficiency of an- giographic recanalization rated on the TICI scale. A possible variable affecting the clinical outcome might be the prolonged procedure time when multiple thrombectomy maneuvers need to be carried out. ${ }^{13}$ In addition, platelet-rich and thick clots may barely be removed with currently available stent retrievers, leading to unsuccessful recanalization and consequently to poor neurologic outcome. ${ }^{8,10,14}$ Furthermore, progressive infarction during prolonged recanalization attempts may also be associated with filling defects in the distal macrovasculature caused by increased regional vascular resistance. ${ }^{15}$

A limitation of this study is its retrospective design. Although the usage of Solitaire or Trevo as the first thrombectomy device was a defining inclusion criterion, other thrombectomy devices may have been used additionally during the procedure. Therefore, the reported maneuver count could not be attributed to 1 specific stent retriever. Aspiration attempts were not performed on a regular basis and, therefore, not evaluated. With this approach as a primary approach, the relationship between the number of maneuvers and recanalization may be different. Operator experience was not analyzed, either. In addition, termination of the thrombectomy procedure was a subjective choice by the operator based on various clinical factors. Thus, there might be some underlying bias.

\section{CONCLUSIONS}

The increasing number of thrombectomy maneuvers is strongly correlated with a decreasing probability of recanalization and of favorable neurologic recovery. Especially, the chance of successful recanalization will decrease below $50 \%$ if recanalization is not achieved within 5 thrombectomy maneuvers. Patients recanalized within 2 maneuvers have the best chance of achieving a good outcome. After 4 thrombectomy maneuvers, there is nearly no chance of good clinical outcome.

Disclosures: Johannes Pfaff-UNRELATED: Payment for Lectures (including service on Speakers Bureaus): Siemens Healthineers; Travel/Accommodations/Meeting Expenses Unrelated to Activities Listed: Stryker Neurovascular. Peter RinglebUNRELATED: Payment for Lectures (including service on Speakers Bureaus): Bayer, Boehringer Ingelheim, Pfizer, Daiichi Sankyo. Simon Nagel—UNRELATED: Consultancy: Brainomix, Boehringer Ingelheim; Grants/Grants Pending: Brainomix*; Payment for Lectures (including service on Speakers Bureaus): Pfizer, Bayer, Medtronic; Travel/Accommodations/Meeting Expenses Unrelated to Activities Listed: Brainomix, Medtronic, Bayer, Boehringer Ingelheim. Christian Herweh-UNRELATED: Consultancy: Brainomix; Payment for Lectures (including service on Speakers Bureaus): Bristol-Myers Squibb; Travel/Accommodations/Meeting Expenses Unrelated to Activities Listed: Stryker. Markus Möhlenbruch—UNRELATED: Board Membership: Codman; Payment for Lectures (including service on Speakers Bureaus): Microvention, Phenox, Stryker. Martin Bendszus_UNRELATED: Board Membership: DSMB for Vascular Dynamics; Consultancy: Codman, Roche, Guerbet; Grants/Grants Pending: DFG, Hopp Foundation, Novartis, Siemens, Guerbet, Stryker, Covidien*; Payment for Lectures (including service on Speakers Bureaus): Novartis, Roche, Guerbet, Teva, Bayer, Codman. Mirko Pham—UNRELATED: Grants/Grants Pending: Guerbet, Comments: project grants; Deutsche Forschungsgemeinschaft, Comments: project grant SFB 1158 TPA3*; Payment for Lectures (including service on Speakers Bureaus): Penumbra, Siemens. *Money paid to the institution. 


\section{REFERENCES}

1. Berkhemer OA, Fransen PS, Beumer D, et al. A randomized trial of intraarterial treatment for acute ischemic stroke. NEngl JMed 2015; 372:11-20 CrossRef Medline

2. Broderick JP, Palesch YY, Demchuk AM, et al. Endovascular therapy after intravenous t-PA versus t-PA alone for stroke. $N$ Engl J Med 2013;368:893-903 CrossRef Medline

3. Campbell BC, Mitchell PJ, Kleinig TJ, et al. Endovascular therapy for ischemic stroke with perfusion-imaging selection. $N$ Engl J Med 2015;372:1009-18 CrossRef Medline

4. Balami JS, Sutherland BA, Edmunds LD, et al. A systematic review and meta-analysis of randomized controlled trials of endovascular thrombectomy compared with best medical treatment for acute ischemic stroke. Int J Stroke 2015;10:1168-78 CrossRef Medline

5. Saver JL, Goyal M, Bonafe A, et al. Stent-retriever thrombectomy after intravenous t-PA vs. t-PA alone in stroke. N Engl J Med 2015; 372:2285-95 CrossRef Medline

6. Jovin TG, Chamorro A, Cobo E, et al. Thrombectomy within $\mathbf{8}$ hours after symptom onset in ischemic stroke. N Engl J Med 2015;372: 2296-306 CrossRef Medline

7. Goyal M, Demchuk AM, Menon BK, et al. Randomized assessment of rapid endovascular treatment of ischemic stroke. $N$ Engl J Med 2015;372:1019-30 CrossRef Medline

8. Kim SK, Yoon W, Kim TS, et al. Histologic analysis of retrieved clots in acute ischemic stroke: correlation with stroke etiology and gra- dient-echo MRI. AJNR Am J Neuroradiol 2015;36:1756-62 CrossRef Medline

9. Tomkins AJ, Schleicher N, Murtha L, et al. Platelet rich clots are resistant to lysis by thrombolytic therapy in a rat model of embolic stroke. Exp Transl Stroke Med 2015;7:2 CrossRef Medline

10. Niesten JM, van der Schaaf IC, van Dam L, et al. Histopathologic composition of cerebral thrombi of acute stroke patients is correlated with stroke subtype and thrombus attenuation. PLOS ONE 2014;9:e88882 CrossRef Medline

11. Weisstanner C, Gratz PP, Schroth G, et al. Thrombus imaging in acute stroke: correlation of thrombus length on susceptibilityweighted imaging with endovascular reperfusion success. Eur Radiol 2014;24:1735-41 CrossRef Medline

12. Seker F, Pfaff J, Wolf M, et al. Impact of thrombus length on recanalization and clinical outcome following mechanical thrombectomy in acute ischemic stroke. J Neurointerv Surg 2016 Sep 15. [Epub ahead of print] CrossRef Medline

13. Dorado L, Millán M, Pérez de la Ossa N, et al. Time to recanalization and risk of symptomatic intracerebral haemorrhage in patients treated with intravenous thrombolysis. Eur J Neurol 2012;19: 1251-55 CrossRef Medline

14. Lamprecht S, Jansen O, Riedel CH. Abstract W MP8: Stent retrievers do not encase clots but hook them within seconds. Stroke 2015; 46(suppl 1):AWMP8

15. Pham M, Bendszus $M$. Facing time in ischemic stroke: an alternative hypothesis for collateral failure. Clin Neuroradiol 2016;26:141-51 CrossRef Medline 